\title{
EXPERIMENTAL ANALYSIS OF WATERPROOFING POLYMERIC PAVEMENTS FOR CONCRETE BRIDGE DECKS
}

Marco Pasetto, Professor, University of Padua, Department of Civil, Environmental and Architectural Engineering - Padova, Italy.Email: marco.pasetto@unipd.it

Giovanni Giacomello, Ph.D. student, University of Padua, Department of Civil, Environmental and Architectural Engineering - Padova, Italy.Email: giovanni.giacomello@unipd.it

doi: 10.2478/ijpeat-2013-0008

\begin{abstract}
On concrete bridge and viaduct decks, traditional bituminous pavements are often subject to rapid degradation, particularly due to precipitation, traffic loadings and chemical attack. Pavement failure can also be due to underlying cracks related to steel reinforcement corrosion. For this reason waterproofing plays an important role in durability of the structure. Waterproofing can be done by means of polymeric binders and aggregates, mixed or applied together in the surface course.
\end{abstract}

The paper summarizes the main results of a study aimed at mechanically characterizing resin-aggregate mixtures (premixed and multi-layers) for bridge waterproofing and paving: two types of resins and several types of natural and artificial/industrial aggregate (EAF slag, C\&D aggregate, limestone and quartz sand) were used. Permanent deformation resistance and adhesion tests were conducted, as well as trials to define the surface characteristics of the product (skid resistance, permeability, macro-texture). The comparison demonstrates that polymeric slurries present better resistance than polymeric multi-layers and bituminous mixtures to permanent deformation at higher temperatures $\left(40\right.$ to $60{ }^{\circ} \mathrm{C}$ ), but show some deficiencies in adhesion properties. However, the surface characteristics of polymeric multi-layers are preferable to those of slurries and traditional bituminous mixtures.

\section{INTRODUCTION}

Bridges and viaducts occur frequently along roads and motorways for crossing over watercourses, low-lying areas and other roads and railways. Many of these structures, due to the effect of increasing traffic loads and climatic stresses, have suffered from accelerated degradation over the years. This degradation has identified the need to study alternative maintenance techniques that are aimed at extending the service life of the surfacings (White and Montani, 1997).

Concrete and steel are the main materials used for constructing the deck of a reinforced concrete bridge. Both materials have characteristics of high resistance, which decrease in different ways. The porosity of the concrete allows the intrusion of de-icing salts and chemical agents that contribute to its deterioration and corrosion of the steel reinforcing. Moisture entering the concrete through the cracks and successive freeze-thaw cycles causes damage to the concrete and steel (Nabar and Mendis, 1997; Silfwerbrand and Paulasson, 1998). 
The damages that these structures suffer over time are mainly due to precipitation, traffic loadings and chemical agents. The precipitation (rain and snow) and chemical agents can attack the steel and concrete and corrode them until parts of the structure fail. Water and snow, coming into contact with the steel, encourage the formation of rust, which increases the dimensions of the steel with the consequent opening of cracks in the concrete. The de-icing salts lead to the intrusion of chlorine ions, which accelerates the corrosion of the reinforcing (White and Montani, 1997).

The repetitiveness of the loads (by transiting vehicles) over time stresses the materials: this damage appears as cracks and fissures on the deck surface, which reduce the area of the section, leading to collapse.

The pavement on bridge decks therefore performs a twofold function: on the one hand it protects the concrete from chemical attack and weather, providing waterproofing; on the other it acts as a sort of filter/distributor of the vehicle loads. Sometimes the damage suffered by the concrete is reflected up through the pavement, which deteriorates over time with the transit of vehicles. Vice versa, the damage that the pavement suffers (permanent deformations, fatigue cracking, detachment of parts, etc.) involves damage to the deck. Cracks and detachments of the pavement allow the intrusion of water, snow and salt (during the winter), which damage the concrete and steel.

The pavements on bridge decks must, therefore, consist of materials with good mechanical properties in terms of surface characteristics, resistance to permanent deformation and fatigue, and adhesion to the support.

Many methods have already been utilized to improve these properties. Traditional systems exist composed of a bituminous layer that performs the function of waterproofing the deck. Two or three layers of asphalt are then laid on top of the waterproofing layer to reduce the tensile stress on the concrete induced by the traffic loads. According to some authors the laying of a waterproofing membrane between the interface between the concrete deck and the asphalt layer of the pavement is necessary in order to increase the water resistance and provide adequate adhesion at the interface between the layers (Zhou and $\mathrm{Xu}, 2009$ ). Skid resistance can be improved by means of pigmented sand aggregate. Other authors suggest using asphalt mixtures with bitumen, that has been modified by the addition of styrene-butadienestyrene (SBS), for trafficable waterproofings: rutting tests have indicated that traditional asphalt concretes suffer greater deformations than those modified with SBS (Park et al., 2009).

Some researchers argue that an asphalt pavement loses its surface characteristics (especially in terms of skid resistance) in about ten years and that detachments and loss of adhesion between pavement and deck occur. They, therefore, suggest using less costly and more long-lasting materials such as epoxy resins, cement concrete and concrete modified with latex (Babaei and Hawkins, 1988).

Other researchers suggest that a good bond of a pavement on concrete decks is to be ascribed to the roughness of the support. Utilizing suitable equipment, the deck should be roughened to allow a better grip of the coating layer (Silfwerbrand and Paulasson, 1998). 
Yet others maintain that a good bonding of the coating, either a polymeric mixture or an asphalt, is to be ascribed to the presence of a thin layer that waterproofs the support (in epoxy resin or methacrylate) (Gillum et al., 2001). On pavements in asphalt or concrete, the laying of a thin layer of polymeric mortars to roughen the surface and obtain a good skid resistance between pavement and tyre has also been studied in Italy, with good results (Pasetto and Zanutto, 1999).

Another solution is the use of different types of polymers or synthetic resins (methacrylic, epoxy, polyurethane and polyester) as substitutes for the bituminous binder. Most of these binders have thermosetting behaviour: with a rise in temperature, the network of molecules that is created during the hardening is refined, forming other networks. Instead, bitumen tends to soften at high temperatures. These binders, therefore, perform better, especially in places with high temperatures, where the use of bitumen would lead to the exuding of the binder (bleeding).

Various studies have been dedicated to the laying methods of these polymeric mixtures, including in trials (Sprinkel, 1997; Knight et al., 2004; Pasetto and Giacomello, 2013). The first method is known as "premixed" and consists of mixing resin and aggregates in opportune quantities to form a mortar that is then laid on the deck (Calvo and Meyers, 1991; Maass, 2003). The second, called "multi-layer", is in a series of steps: 1) laying of a layer of binder (usually a few millimetres thick), 2) dusting of aggregate on the binder surface until saturation, 3) elimination of the aggregate in excess after setting, 4) laying of a new layer of binder (as in step 1) to then pass to steps 2 and 3. Just two layers of binder and aggregate are usually laid to form a pavement with pronounced surface characteristics. The final thickness normally reaches $8 \mathrm{~mm}$ to $10 \mathrm{~mm}$ (Sprinkel 2001; Stenko, 2001).

Some authors have demonstrated, with in situ trials, that the use of polymeric coatings based on epoxy resins confers many benefits: rapid intervention, low permeability, improvement of skid resistance, better ratio cost/useful life of the deck, excellent adhesion to the concrete support (not affected by the presence of alkalinity). The authors indicate that the system is suited to the repair and maintenance of old bridge decks. Even if the epoxy binder has a low modulus of elasticity, the pavement has good resistance and flexibility (Mendis, 1987; Dimmick, 1997; Nabar and Mendis, 1997; Zalatimo and Fowler, 1997).

The "premixed" method has been widely used in the USA to delay the process of corrosion in the concrete (preventing the penetration of chlorine ions and moisture): a waterproof coating of epoxy mortar has demonstrated, also 15 years after laying, a high resistance to wear and good maintenance of the surface characteristics, extending the service life of the pavement and deck (Dimmick, 1996).

The experimental programme presented in this paper studies the performances of materials intended for waterproofing surface courses applied to concrete bridge decks. The use of epoxy polymers has been evaluated, comparing the properties of different laying methods through tests of physical (surface characteristics) and mechanical characterization (permanent deformations and adhesion to the support). 


\section{MATERIALS}

The materials used include various types of binders and marginal and natural aggregates (electric arc furnace steel slag, limestone, quartz sand, bauxite, etc.).

The binders are two types of resin, two types of primer and one bitumen. Binder A (Table 1) is a two-component product (a monomer and a catalyst) of epoxypolyurethane, which hardens at ambient temperature. It can be laid alone to form a waterproofing layer (1 - $2 \mathrm{~mm}$ approx., following the "multi-layer" solution), or mixed with aggregates to form a mortar ("premixed" solution). Its principal characteristics are ductility, impermeability, tenacity and chemical inertia. The mortar possesses a flexural strength of $16 \mathrm{MPa}$ and a compressive strength of more than 10 MPa (EN 196-1:2005). Binder B (Table 2) is a two-component (a monomer and a catalyst) modified polyurethane resin. This binder was used only for the multi-layer method.

Preliminary operations were involved prior to laying the binder or mortar, for both types (A and B). The surface of the support was first cleaned and sanded to eliminate any parts that were fragile or could break off. A layer of primer was then laid, which had the function of aiding the adhesion of the binder, or mortar, to the cement concrete support. Primer A (Table 1) is a synthetic epoxy material and possesses optimal resistance to water and saline solutions. Primer B (Table 2) is a twocomponent methacrylic resin, it is colourless and possesses low viscosity.

Specimens were also prepared with an asphalt mixture (BM), which was produced with a bitumen traditionally used in Italy (50/70 pen) (Table 3$)$. To obtain a better adhesion to the concrete, a bituminous layer, composed of polyester covered in bitumen and chippings, with a waterproofing function, was interposed between the support and asphalt.

Tables 1 and 2 summarize the principal properties of the synthetic binders and primers. The physical-mechanical properties of the bituminous layer and bitumen are shown in Table 3.

Table 1. Properties of synthetic binder type A and primer type A

\begin{tabular}{|c|c|c|c|c|c|}
\hline Parameter & Standard & Binder A & Parameter & Standard & Primer A \\
\hline Density $\left[\mathrm{Mg} / \mathrm{m}^{3}\right]$ & $\begin{array}{c}\text { ASTM } \\
\text { D792 }\end{array}$ & 1,15 & $\begin{array}{c}\text { Slant shear } \\
\text { strength [MPa] }\end{array}$ & $\begin{array}{c}\text { EN } \\
12615\end{array}$ & $>12$ \\
\hline $\begin{array}{c}\text { Superficial } \\
\text { hardness [Shore A] }\end{array}$ & $\begin{array}{c}\text { ASTM } \\
\text { D2240 }\end{array}$ & 60 & $\begin{array}{c}\text { Compressive } \\
\text { strength [MPa] }\end{array}$ & $\begin{array}{c}\text { ASTM } \\
\text { D695 }\end{array}$ & $>60$ \\
\hline $\begin{array}{c}\text { Tensile strength } \\
{[\mathrm{MPa}]}\end{array}$ & $\begin{array}{c}\text { ASTM } \\
\text { D638 }\end{array}$ & $\geq 2$ & $\begin{array}{c}\text { Elastic Modulus in } \\
\text { compression [MPa] }\end{array}$ & $\begin{array}{c}\text { ASTM } \\
\text { D695 }\end{array}$ & $>2950$ \\
\hline $\begin{array}{c}\text { Tensile } \\
\text { extensibility [\%] }\end{array}$ & $\begin{array}{c}\text { ASTM } \\
\text { D638 }\end{array}$ & $\geq 100$ & $\begin{array}{c}\text { Flexural-tensile } \\
\text { strength [MPa] }\end{array}$ & $\begin{array}{c}\text { ASTM } \\
\text { D695 }\end{array}$ & $>30$ \\
\hline $\begin{array}{c}\text { Strength of } \\
\text { coating [MPa] }\end{array}$ & $\begin{array}{c}\text { ASTM } \\
\text { D4541 }\end{array}$ & $\geq 1,85$ & $\begin{array}{c}\text { Bond strength by } \\
\text { pull-off test [MPa] }\end{array}$ & EN 1542 & $>5$ \\
\hline
\end{tabular}


Table 2. Properties of synthetic binder type $B$ and primer type $B$

\begin{tabular}{|c|c|c|c|c|c|}
\hline Parameter & Standard & Binder B & Parameter & Standard & Primer B \\
\hline $\begin{array}{c}\text { Density at } 25^{\circ} \mathrm{C} \\
{\left[\mathrm{Mg} / \mathrm{m}^{3}\right]}\end{array}$ & ISO 2811 & 0,99 & $\begin{array}{c}\text { Tensile strength } \\
{[\mathrm{MPa}]}\end{array}$ & ISO 527 & 13,8 \\
\hline $\begin{array}{c}\text { Curing time } \\
\text { at } 20^{\circ} \mathrm{C}[\mathrm{s}]\end{array}$ & ISO 527 & $\begin{array}{c}3600- \\
7200\end{array}$ & $\begin{array}{c}\text { Elongation at max. } \\
\text { strength [\%] }\end{array}$ & ISO 527 & 1,3 \\
\hline $\begin{array}{c}\text { Tensile strength at } \\
20^{\circ} \mathrm{C}[\mathrm{MPa}]\end{array}$ & ISO 527 & 11 & $\begin{array}{c}\text { Modulus of } \\
\text { elasticity [MPa] }\end{array}$ & ISO 527 & 1500 \\
\hline $\begin{array}{c}\text { Elongation at } \\
\text { Fracture, } 20^{\circ} \mathrm{C}[\%]\end{array}$ & ISO 527 & 250 & $\begin{array}{c}\text { Elongation at } \\
\text { fracture [\%] }\end{array}$ & ISO 527 & 1,3 \\
\hline $\begin{array}{c}\text { Elastic Modulus at } \\
20^{\circ} \mathrm{C}[\mathrm{MPa}]\end{array}$ & ISO 527 & 82,4 & $\begin{array}{c}\text { Density at } 20^{\circ} \mathrm{C} \\
{\left[\mathrm{Mg} / \mathrm{m}^{3}\right]}\end{array}$ & ISO 1183 & 1,16 \\
\hline
\end{tabular}

Table 3. Properties of bituminous layer and of bitumen (50/70 pen)

\begin{tabular}{|c|c|c|c|c|c|}
\hline Parameter & Standard & BM & Parameter & Standard & Bitumen \\
\hline Thickness [mm] & - & 4 & $\begin{array}{c}\text { Penetration at } \\
25^{\circ} \mathrm{C}[0.1 \mathrm{x} \mathrm{mm}]\end{array}$ & EN 1426 & 65 \\
\hline Extensibility [\%] & $\begin{array}{c}\text { ASTM } \\
\text { D638 }\end{array}$ & $>105$ & $\begin{array}{c}\text { Softening point } \\
\text { Ring \& Ball [ }\left[{ }^{\circ} \mathrm{C}\right]\end{array}$ & EN 1427 & 45 \\
\hline $\begin{array}{c}\text { Tensile strength } \\
{[\mathrm{MPa}]}\end{array}$ & $\begin{array}{c}\mathrm{ASTM} \\
\text { D638 }\end{array}$ & $>2,5$ & $\begin{array}{c}\text { Fraass breaking } \\
\text { point }\left[{ }^{\circ} \mathrm{C}\right]\end{array}$ & $\begin{array}{c}\mathrm{EN} \\
12593\end{array}$ & $\leq-8$ \\
\hline $\begin{array}{c}\text { Bond strength by } \\
\text { pull-off test [MPa] }\end{array}$ & $\begin{array}{c}\mathrm{UNI} \mathrm{EN} \\
1542\end{array}$ & 2,5 & $\begin{array}{c}\text { Dynamic viscosity } \\
\text { at } 60^{\circ} \mathrm{C}[\mathrm{Pa} \cdot \mathrm{s}]\end{array}$ & $\begin{array}{c}\mathrm{EN} \\
12596\end{array}$ & $\geq 145$ \\
\hline $\begin{array}{c}\text { Tensile modulus } \\
{[\mathrm{MPa}]}\end{array}$ & $\begin{array}{c}\mathrm{ASTM} \\
\text { D638 }\end{array}$ & $>9$ & $\begin{array}{c}\text { Ductility at } 25^{\circ} \mathrm{C} \\
{[\mathrm{mm}]}\end{array}$ & $\begin{array}{c}\mathrm{ASTM} \\
\mathrm{D} 113\end{array}$ & $\geq 800$ \\
\hline
\end{tabular}

The aggregates used are: quartz sand (QS), natural limestone (L), electric arc furnace steel slags (SS), recycled material (RM) and bauxite (B). The physical-mechanical properties of the aggregates are summarized in Table 4. 
Table 4. Physical and mechanical characteristics of the aggregate: Quartz Sand (QS), EAF steel slag (SS), Limestone (L), Recycled material (RM), Bauxite (B)

\begin{tabular}{|c|c|c|c|c|c|c|c|c|c|}
\hline Parameter & Standard & QS & \multicolumn{2}{|c|}{ SS } & \multicolumn{2}{|c|}{$\mathrm{L}$} & \multicolumn{2}{|c|}{$\mathrm{RM}$} & B \\
\hline & Fractions & - & $0 / 4$ & $4 / 8$ & $0 / 5$ & $5 / 10$ & $0 / 5$ & $5 / 10$ & - \\
\hline $\begin{array}{l}\text { Los Angeles } \\
\text { coefficient [\%] }\end{array}$ & $\begin{array}{c}\text { EN } \\
1097-2\end{array}$ & - & - & 11,5 & - & 16 & - & 23,6 & - \\
\hline $\begin{array}{l}\text { Equivalent } \\
\text { in sand [\%] }\end{array}$ & $\begin{array}{c}\text { EN 933- } \\
8\end{array}$ & 95 & 87 & - & 70 & - & 98 & - & 98 \\
\hline $\begin{array}{c}\text { Shape index } \\
{[\%]}\end{array}$ & $\begin{array}{c}\text { EN 933- } \\
4\end{array}$ & - & 19 & 15 & - & 5 & 15 & 22 & - \\
\hline $\begin{array}{c}\text { Flakiness index } \\
{[\%]}\end{array}$ & $\begin{array}{c}\text { EN 933- } \\
3\end{array}$ & - & 29 & 8 & - & 8 & 16 & 32 & - \\
\hline $\begin{array}{c}\text { Grain dry } \\
\text { density }\left[\mathrm{Mg} / \mathrm{m}^{3}\right]\end{array}$ & $\begin{array}{l}\text { CNR } \\
64 / 78 \\
\end{array}$ & 2,78 & 3,9 & 3,92 & 2,76 & 2,72 & 2,6 & 2,64 & 2,81 \\
\hline $\begin{array}{c}\text { Grain bulk } \\
\text { density }\left[\mathrm{Mg} / \mathrm{m}^{3}\right]\end{array}$ & $\begin{array}{l}\text { CNR } \\
63 / 78\end{array}$ & 2,57 & 3,9 & 3,87 & 2,55 & 2,64 & 2,5 & 2,48 & 2,55 \\
\hline $\begin{array}{l}\text { Aggregate bulk } \\
\text { density }\left[\mathrm{Mg} / \mathrm{m}^{3}\right]\end{array}$ & $\begin{array}{l}\text { CNR } \\
62 / 78\end{array}$ & 1,48 & 2,1 & 2,13 & 1,48 & 1,36 & 1,3 & 1,32 & 1,52 \\
\hline
\end{tabular}

The quartz sand and bauxite are very similar aggregates: they have a low quantity of fine particles and an intermediate specific weight between the steel slags and recycled material. Two grading fractions were used for the natural limestone and recycled aggregate: $0 / 5$ and 5/10 mm. Two were also used for the steel slags: 0/4 and 4/8 mm. The steel slags have the highest specific weight, a low content of fine particles and high abrasion and Los Angeles fragmentation resistance (low value of the Los Angeles coefficient). A low value of the flakiness and shape index, as in the case of the limestone and steel slags, indicates a low presence of aggregates of lenticular and elongated shape: greatly sought after qualities to obtain a good asphalt for a surface course. The recycled material, a mixture of glass and material from construction and demolition, has properties with among the highest values: low resistance to fragmentation and abrasion and a more elongated shape of the aggregates than the other materials.

The studied solutions regard both the "premixed" (PR) and the "multi-layer/multiplelayer" (ML) laying methods.The mixtures prepared according to the "premixed" method were further divided into two families, depending on the grading envelope utilized for the mix design: the type 1 (T1) envelope, already used (Pasetto and Giacomello, 2013) for the laying of mixtures, and the type 2 (T2) envelope used for an asphalt for surface courses (SITEB, Italian Society of Bitumen Technicians).

With the first type of envelope (T1) polymeric mixtures were prepared with quartz sand (PR-T1-QS), steel slags (PR-T1-SS) and recycled aggregate (PR-T1-RM). With the second type of envelope (T2) polymeric conglomerates were produced with limestone (PR-T2-L) and steel slags (PR-T2-SS). Only resin of type A was used for 
the preparation of both types. For the preparation of the asphalt, two systems were adopted that are traditionally used in northern Italy: one with limestone (BM-T2-L) and one with steel slags (BM-T2-SS). For the multiple-layer type, a grading envelope from the literature (Pasetto and Giacomello, 2013) was used and polymeric mixtures were prepared with quartz sand (ML-QS), steel slags (ML-SS), recycled aggregate (ML-RM) and bauxite (ML-B). The type B binder was only used to produce ML-B specimens. The proportions between the grading fractions used are indicated in table 5. The grading of the mixtures and grading envelopes are reported in figures 1,2 and 3.

Table 5. Aggregate type and particle size distribution of the mixtures composition of the mixtures

\begin{tabular}{|c|c|c|c|c|c|c|c|c|c|c|}
\hline \multirow[t]{2}{*}{$\begin{array}{c}\text { Mixture } \\
\text { composition }\end{array}$} & $\begin{array}{c}\text { Fraction } \\
{[\mathrm{mm}]}\end{array}$ & \multicolumn{9}{|c|}{ Quantity [\%] } \\
\hline & & $\begin{array}{c}\text { BM- } \\
\text { T2-L } \\
\& \\
\text { PR-T2 }\end{array}$ & $\begin{array}{c}\text { BM-T2- } \\
\text { SS \& } \\
\text { PR-T2- } \\
\text { SS }\end{array}$ & $\begin{array}{l}\text { PR- } \\
\text { T1- } \\
\text { RM }\end{array}$ & $\begin{array}{l}\text { PR- } \\
\text { T1- } \\
\text { QS }\end{array}$ & $\begin{array}{l}\text { PR- } \\
\text { T1- } \\
\text { SS }\end{array}$ & $\begin{array}{l}\text { ML- } \\
\text { QS }\end{array}$ & $\begin{array}{l}\text { ML- } \\
\text { SS }\end{array}$ & $\begin{array}{l}\text { ML- } \\
\text { RM }\end{array}$ & $\begin{array}{c}\text { ML- } \\
\text { B }\end{array}$ \\
\hline \multirow{2}{*}{ Limestone } & $0 / 5$ & 48 & - & 40 & - & - & - & - & - & - \\
\hline & $5 / 10$ & 45 & - & - & - & - & - & - & - & - \\
\hline \multirow{2}{*}{ EAF steel slags } & $0 / 4$ & - & 70 & - & - & 100 & - & 100 & - & - \\
\hline & $4 / 8$ & - & 22 & - & - & - & - & - & - & - \\
\hline \multirow{2}{*}{$\begin{array}{l}\text { Recycling } \\
\text { material }\end{array}$} & $0 / 5$ & - & - & 45 & - & - & - & - & 100 & - \\
\hline & $5 / 10$ & - & - & 15 & - & - & - & - & - & - \\
\hline Quartz sand 1 & & - & - & - & 100 & - & - & - & - & - \\
\hline Quartz sand 2 & & - & - & - & - & - & 100 & - & - & - \\
\hline Bauxite & & - & - & - & - & - & - & - & - & 100 \\
\hline $\begin{array}{c}\text { Mineral filler } \\
\text { (additive) }\end{array}$ & & 7 & 8 & - & - & - & - & - & - & - \\
\hline
\end{tabular}




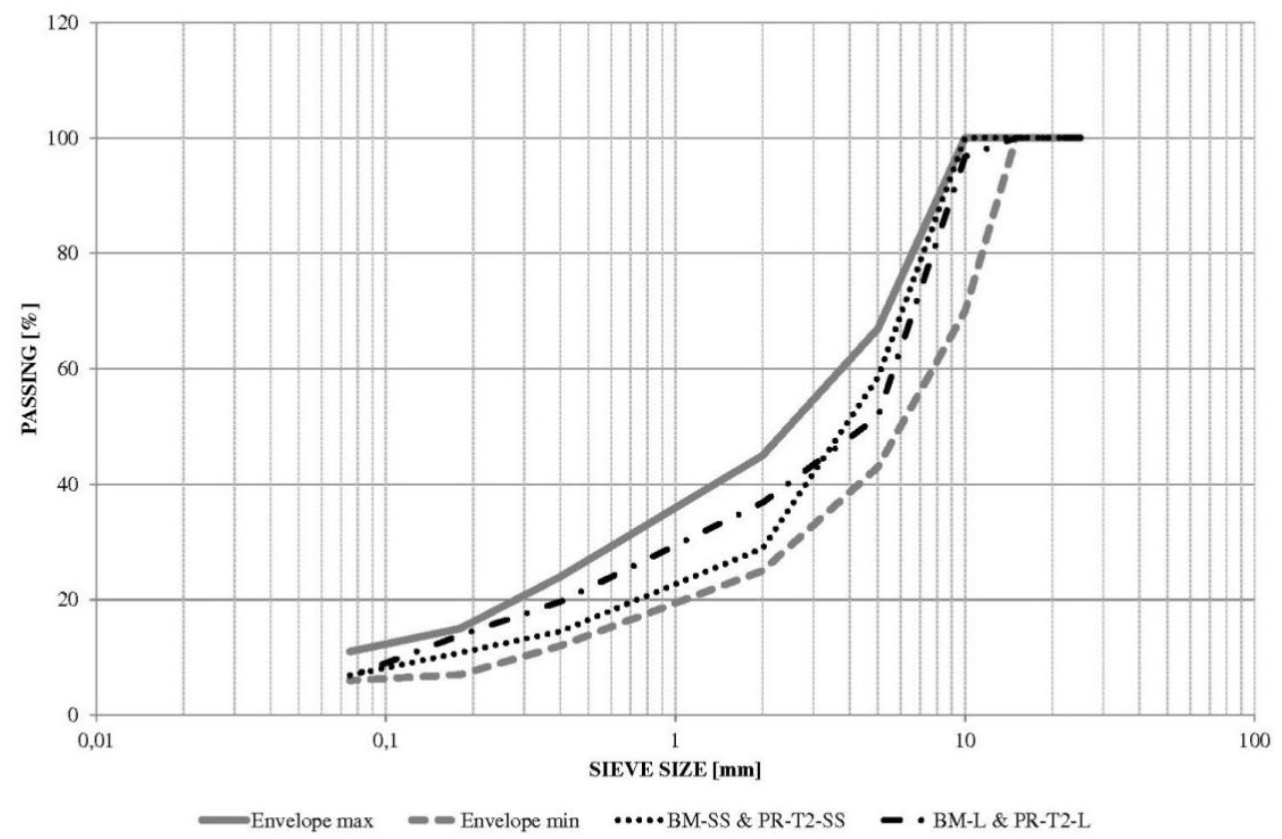

Figure 1. Grading envelope and curves for BM-T2-SS,BM-T2-L, PR-T2-L e PRT2-SS mixtures (asphalt mixtures BM and premixed waterproofings PR)

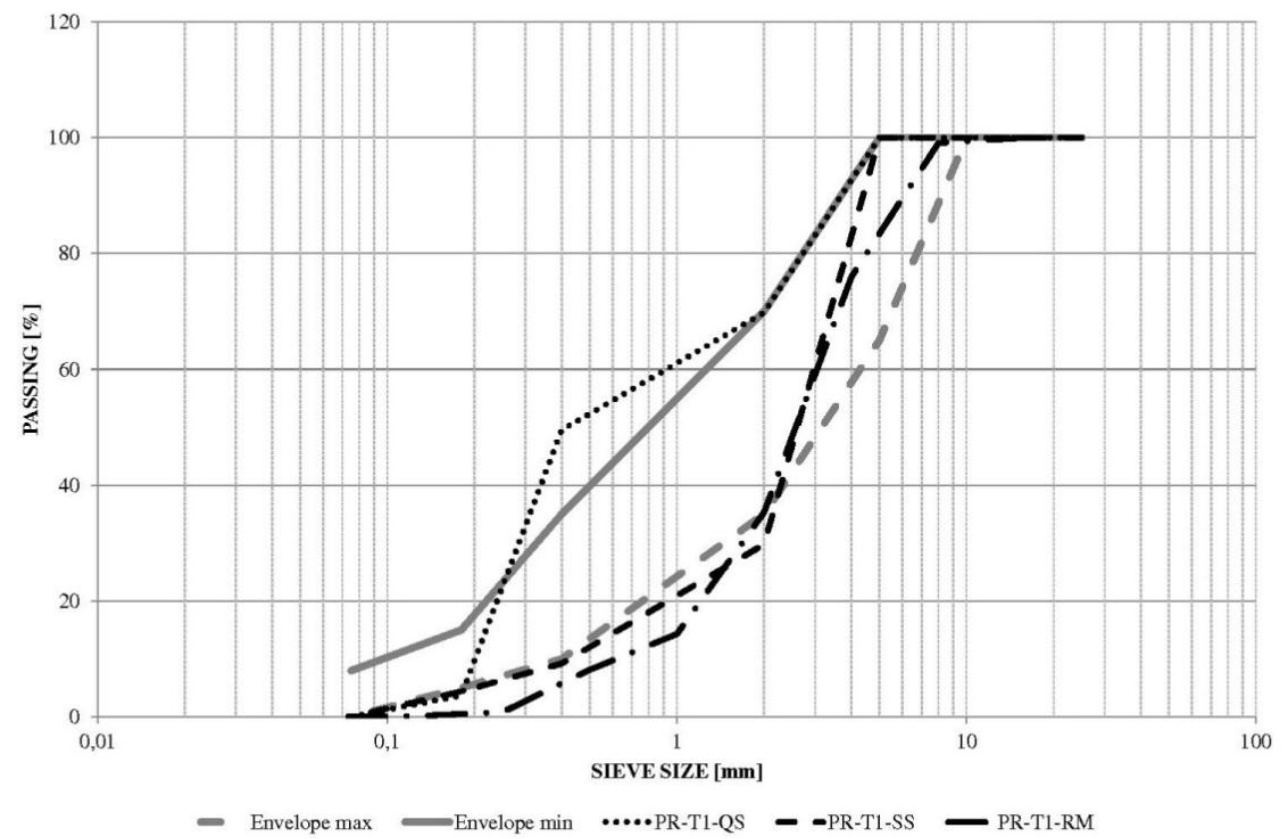

Figure 2. Grading envelope and curves for PR-T1-QS, PR-T1-SS e PR-T1-RM mixtures (premixed waterproofings PR)

The mixtures with the "premixed" laying type were produced following a precise procedure. After having cleared impurities from the surface of the concrete support, the primer was prepared (mixing a monomer and a catalyst) and the mortar (initially mixing the binder with an adequate amount of catalyst and then also with the aggregate). Having laid the primer, the polymeric coating was added after an interval of a few minutes. The specimen was then left to rest for a day to allow the mortar to set. 


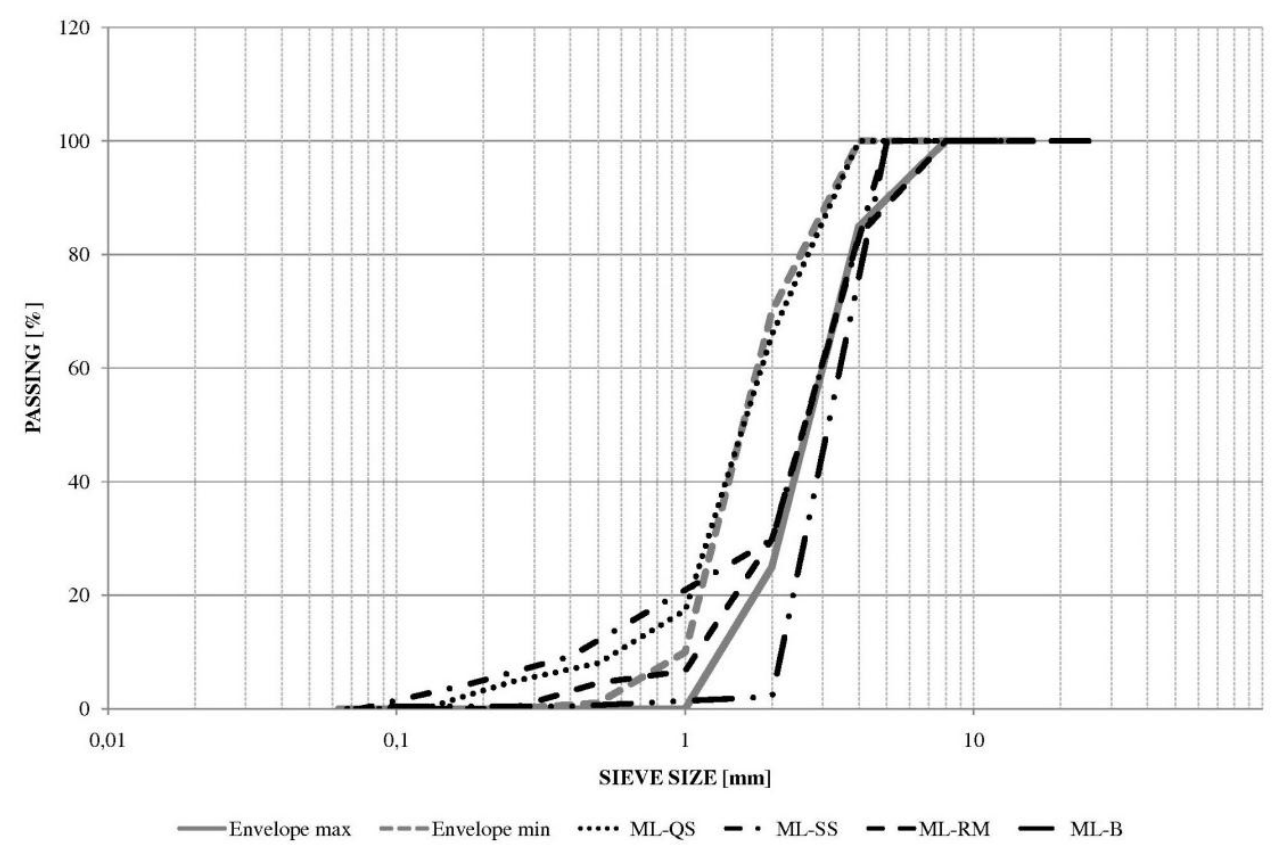

Figure 3. Grading envelope and curves for ML-QS, ML-SS, ML-RM e ML-B mixtures (multi-layer waterproofings $\mathrm{ML}$ )

In the case of mixtures with the "multi-layer" type of laying the procedure followed was slightly different. Having cleaned the surface of the support, prepared and laid the primer, a thin layer of binder (obtained mixing resin and catalyst) was laid. Before the binder set, the aggregate was dusted onto the surface until it was saturated. After setting (one day of rest), the excess aggregate was removed with a blast of air. A second layer of binder was laid on the aggregate remaining stuck to the support, and the aggregate re-applied, until the surface was saturated. After another day of rest, the polymeric pavement was ready.

Just a single layer of aggregate was scattered in the case of the type B resin, because there is not only the primer beneath the binder, but also another layer of waterproofing resin. The concrete supports are $300 \mathrm{~mm}$ long, $400 \mathrm{~mm}$ wide and $30 \mathrm{~mm}$ thick. However, the final thickness of the specimen varies according to the type of coating: in the "multi-layer" case a pavement can be $15 \mathrm{~mm}$, while in the "premixed" case it may reach approx. $20 \mathrm{~mm}$ (like the pavement in asphalt).

\section{METHODS}

The first tests conducted on the specimens were the measurements of surface characteristics. These are very important for pavements on bridges with a concrete deck because they must offer optimal adhesion between tyre and road surfacing. The macro-texture, by means of the height in sand (EN 13036-1:2010), skid resistance (PTV - Pendulum Test Value index) by the PendulumTest (EN 13036-4:2011), and permeability (EN 13036-3:2006) were, therefore, evaluated.

The macro-texture of the pavement was measured according to the protocol indicated in the EN standard. Known quantities of microspheres are spilled onto the pavement and spread to form a circular area, until all the elements have filled the voids between aggregates. The two diameters of the circular area are then measured and, the volume 
of spheres being known, the macro-texture of the pavement is calculated in terms of height in spheres.

The skid resistance is measured by a rubber sliding block of determined characteristics connected to a pendulum that oscillates without friction nominally around a pivot. The sliding block, made to fall from a precise height, rubs against the surface of the pavement and loses a certain amount of kinetic energy. The measurement taken with this instrument expresses the amount of energy lost after the rubbing of the sliding block on the pavement: the smoother the pavement is the lower the value of skid resistance will be.

The permeability was measured as the time (in seconds) in which a known quantity of water, contained in a test-tube, leaks from beneath a rubber sealing ring pressed by a mass (of known weight).

The specimens also underwent rutting (wheel tracking) tests (EN 12697-22:2007) using the small device to Procedure B. The test simulates the repeated transit of heavy vehicles on the pavement, to register the permanent deformation over time. The number of transits $\left(10^{4}\right.$ cycles $)$ simulated that of the average traffic on Italian roads by means of a rubber wheel (assimilating a vehicle tyre). The tests were done at temperatures of $0{ }^{\circ} \mathrm{C}, 20{ }^{\circ} \mathrm{C}, 40{ }^{\circ} \mathrm{C}$ and $60{ }^{\circ} \mathrm{C}$, in order to understand the thermosetting behaviour of the epoxy resins.

In all cases the adhesion of the pavement to the concrete support was tested. The standard EN 1542:2000 required cylindrical specimens to be produced of approximately $50 \mathrm{~mm}$ in diameter milling the material with a coring rig, to a depth of approximately $15 \mathrm{~mm}$ into the underlying concrete layer. A round peg was then glued onto each specimen with epoxy adhesive (prescribed by the standard), on which tensile stress was exerted until the specimen failed. The protocol prescribes that the tension increase must be progressive and no more than $0.05 \mathrm{MPa} / \mathrm{s}$.

\section{RESULTS AND DISCUSSION}

The tests to establish the surface properties of the pavements were conducted on each coating, doing three measurements with the macro-texture by patch method, five with the Pendulum Test and three for the permeability. The results are shown in Table 6.

Table 6. Mean value of height in sand, Pendulum Test skid resistance and permeability

\begin{tabular}{|c|c|c|c|c|c|c|c|c|c|c|c|}
\hline Coating type & $\begin{array}{c}\text { PR- } \\
\text { T1- } \\
\text { QS }\end{array}$ & $\begin{array}{c}\text { PR- } \\
\text { T1- } \\
\text { SS }\end{array}$ & $\begin{array}{c}\text { PR- } \\
\text { T1- } \\
\text { RM }\end{array}$ & $\begin{array}{c}\text { PR- } \\
\text { T2- } \\
\text { SS }\end{array}$ & $\begin{array}{c}\text { PR- } \\
\text { T2- } \\
\text { L }\end{array}$ & $\begin{array}{c}\text { BM } \\
- \text { T2- } \\
\text { L }\end{array}$ & $\begin{array}{c}\text { BM } \\
- \text { T2- } \\
\text { SS }\end{array}$ & $\begin{array}{c}\text { ML } \\
-B\end{array}$ & $\begin{array}{c}\text { ML } \\
-Q S\end{array}$ & $\begin{array}{c}\text { ML } \\
\text {-SS }\end{array}$ & $\begin{array}{c}\text { ML- } \\
\text { RM }\end{array}$ \\
\hline $\begin{array}{c}\text { Height } \\
\text { in sand [mm] }\end{array}$ & 0,32 & 0,60 & 0,58 & 0,28 & 0,36 & 0,72 & 0,52 & 0,46 & 1,54 & 2,11 & 2,31 \\
\hline Mean PTV [-] & 21 & 71 & 86 & 31 & 36 & 116 & 95 & 76 & 104 & 114 & 99 \\
\hline Permeability [s] & $>180$ & $>180$ & 585 & $>180$ & $>180$ & 163 & 184 & 742 & 21 & 18 & 14 \\
\hline
\end{tabular}


The tests for measuring the surface characteristics provided clear indications, even during the phase of producing the pavements, especially in the cases of the multi-layer specimens. In any case the surface characteristics vary according to the type of aggregate used and the laying method.

The coatings produced with the multi-layer method, compared with those of the premixed method, provide much more satisfactory results in terms of surface characteristics: the macro-texture and skid resistance are much better. Almost all the pavement types show a macro-texture of the "average" type for Italy (values between 0.40 and $0.80 \mathrm{~mm}$ in terms of height) and only the multi-layer coatings arrive at macro-textures of the "very rough" type (values of above $1.20 \mathrm{~mm}$ ). These values make sense observing that the aggregates create much greater roughness when the multi-layer method is used (Figure 4).

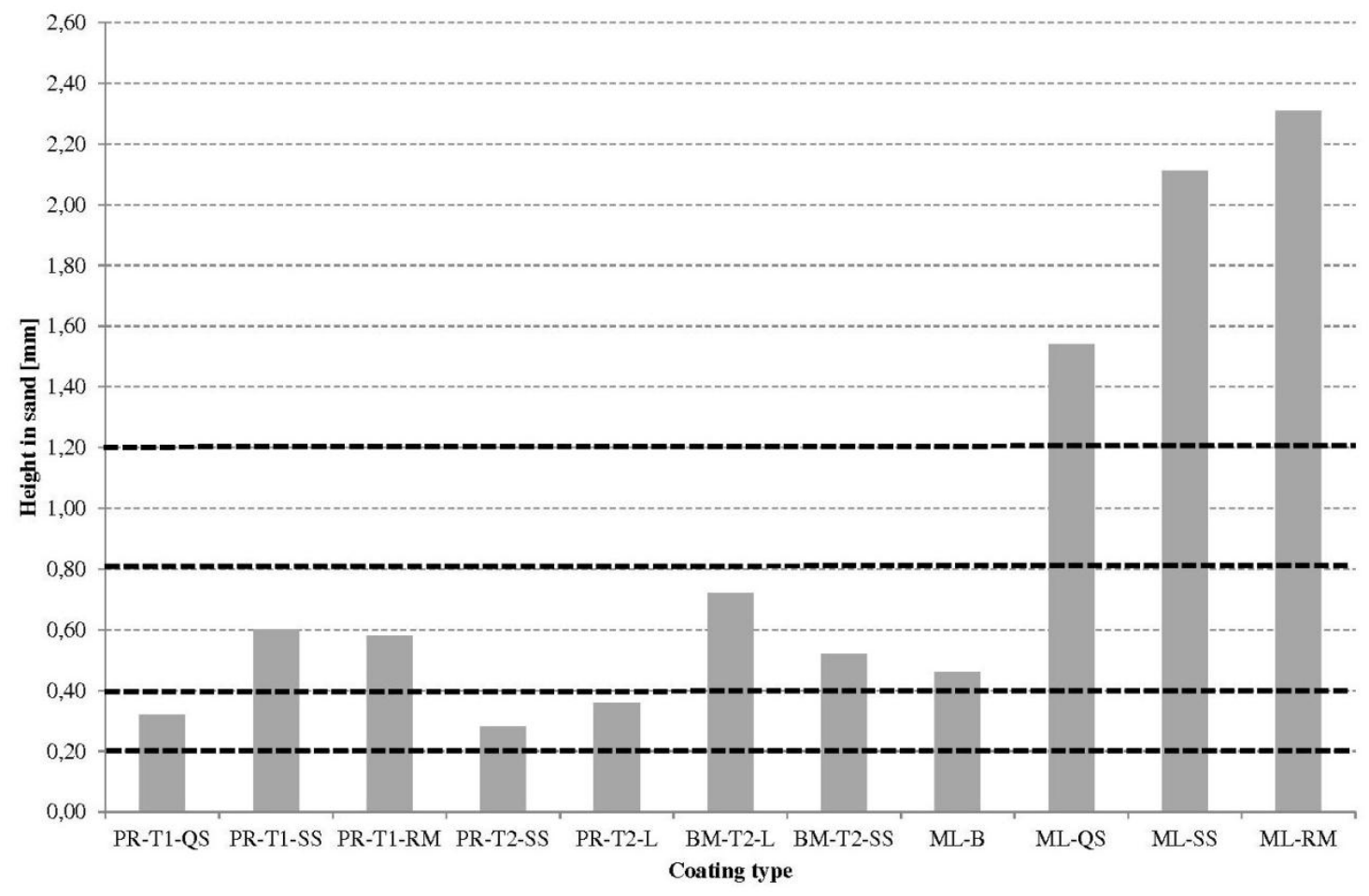

Figure 4. Mean value of macro-texture for each coating type

In terms of skid resistance, almost all types of coating have a surface that is "antiskid par excellence" (values above 65). In the same way as the macro-texture, the multilayer coatings and asphalt have better skid resistance (Figure 5).

The recycled material has good roughness in both cases (premixed and multi-layer waterproofing) and is an antiskid surfacing par excellence (in terms of skid resistance as defined in Italy). The steel slags instead lead to passable results. The coatings with a type 2 lithic matrix have good surface characteristics if bitumen is used as the binder, but not with the polymeric binder. This is confirmed visually: the resin tends to fill the voids between the aggregates creating a rather smooth surface, whereas the bitumen, covering the single grains of aggregate, allows them to retain their shape. In this way, the global properties of the bituminous pavement are better than those with a polymeric binder. 
The permeability measured confirms what has already been described. The coatings with smoother surfaces impede water seepage and therefore have lower values of permeability. Conversely, the multi-layer pavements, which maintain greater roughness of the aggregates, allow better water drainage. The multi-layer with bauxite aggregate coating has values intermediate between those of the asphalt and those found on pavements of the premixed type (table 6).

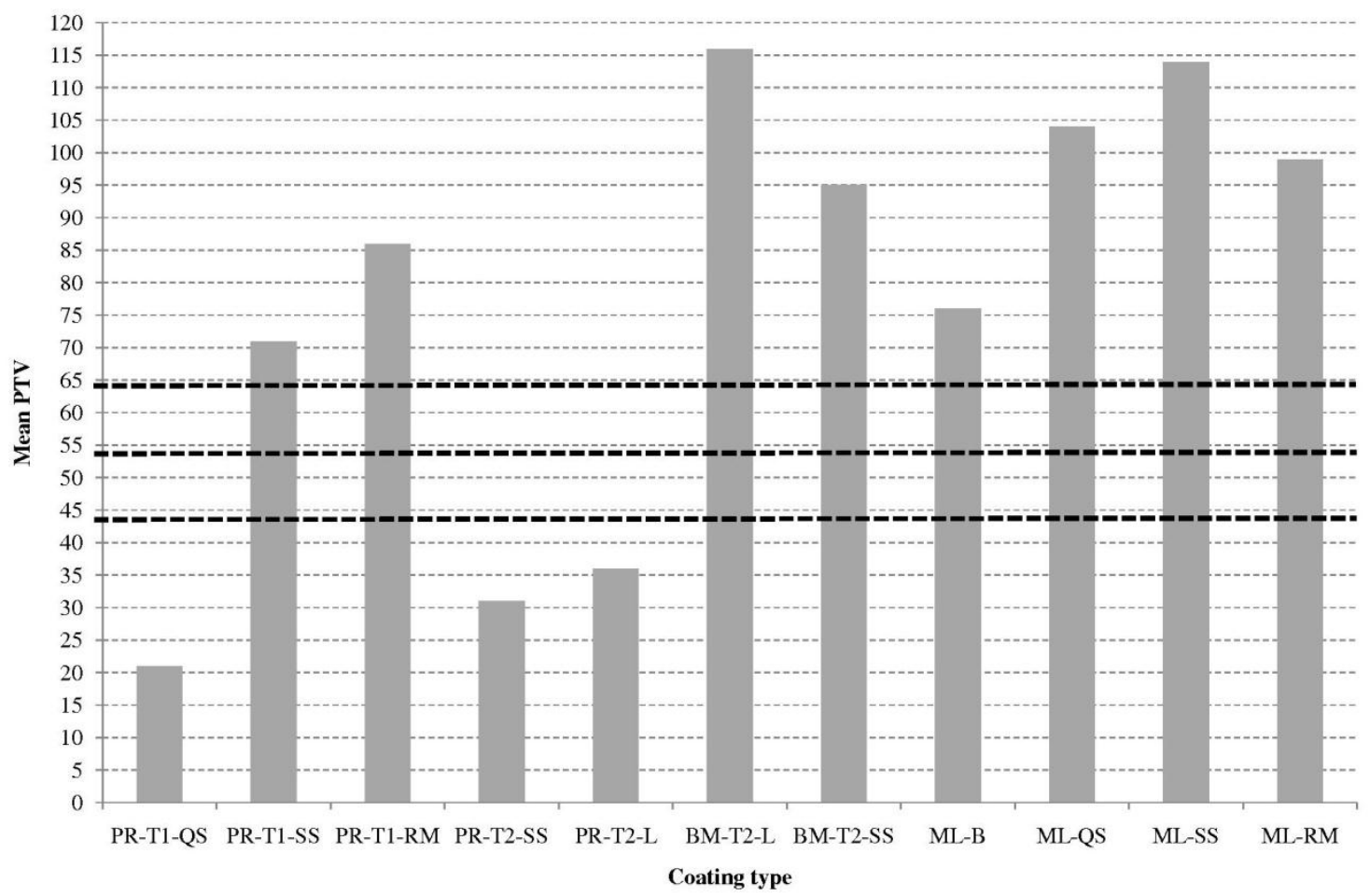

Figure 5. Mean value of skid resistance for any coating type

The results of the tests with the wheel tracking device are reported in Figures 6 and 7 .

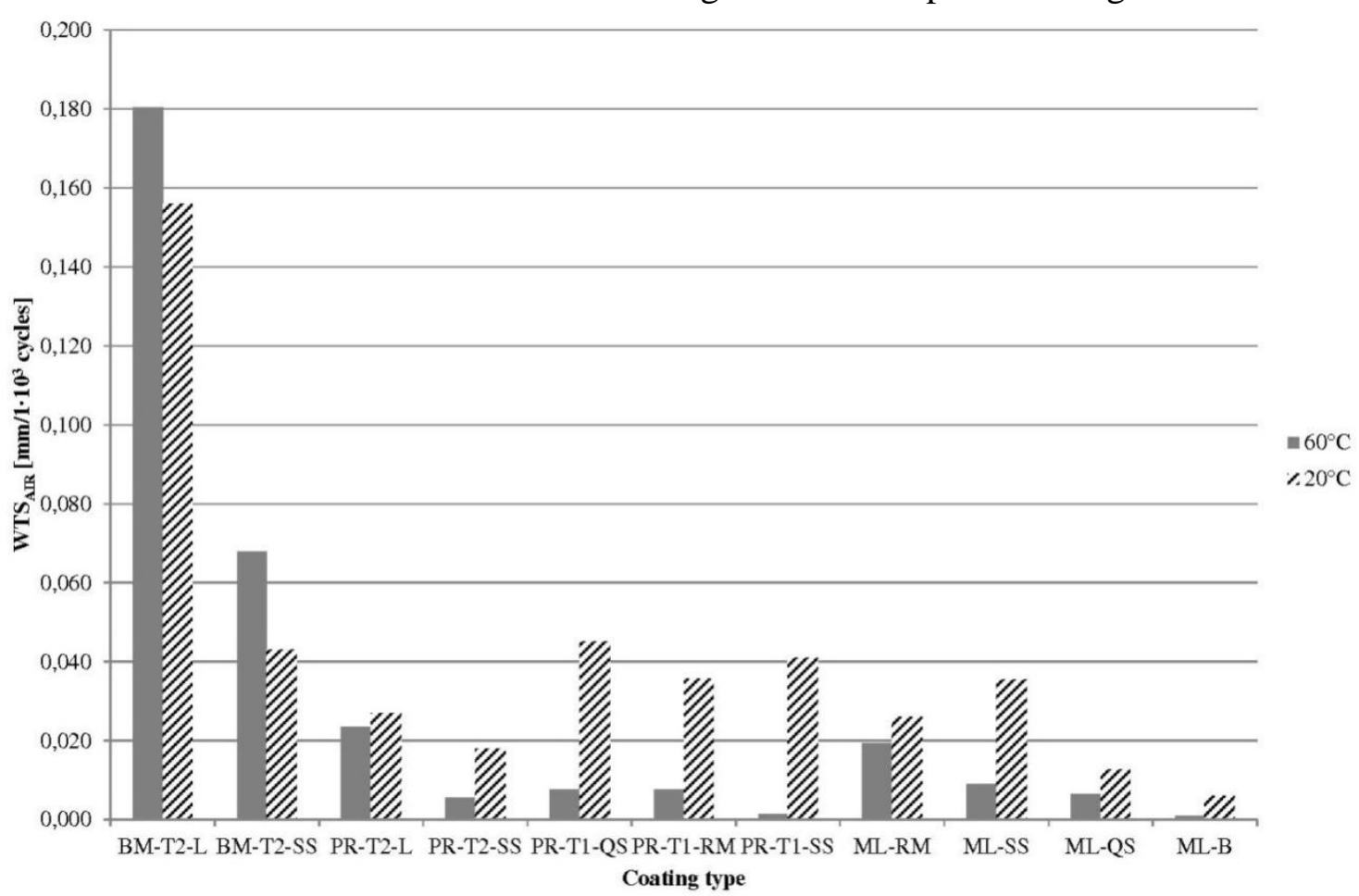

Figure 6. $\mathrm{WTS}_{\mathrm{AIR}}$ at $20^{\circ} \mathrm{C}$ and $60^{\circ} \mathrm{C}$ for each coating type 
In each test, the parameter $\mathrm{WTS}_{\mathrm{AIR}}$ was obtained (as reported in the EN standard), which is the slope of the curve of deformation in millimetres per $10^{3}$ loading cycles. The calculation consists in subtracting the value of the height of the deformation at 5,000 cycles from that at 10,000 cycles, and dividing the result by 5 .

It was possible to ascertain immediately that the polymeric binders possess thermosetting behaviour, due to their chemical composition. In fact, the network of molecules becomes complete, stiffening the polymeric matrix, with the increasing of the temperature.

The polymeric coatings with type 2 lithic matrix react better to permanent deformations than the bituminous ones. In addition, the asphalt with slags performs better than that with limestone, as found previously (Pasetto and Baldo, 2012).

The multi-layer polymeric coatings suffer more from an accumulation of permanent deformations than the same coatings of the premixed type (Figure 6).

In all the cases analysed, the polymeric coatings (premixed and multi-layer) have shown a low predisposition to permanent deformation at high temperatures $\left(60{ }^{\circ} \mathrm{C}-\right.$ $\left.40{ }^{\circ} \mathrm{C}\right)$ and, vice versa, a high predisposition at lower temperatures $\left(0{ }^{\circ} \mathrm{C}-20{ }^{\circ} \mathrm{C}\right)$ (Figure 7).

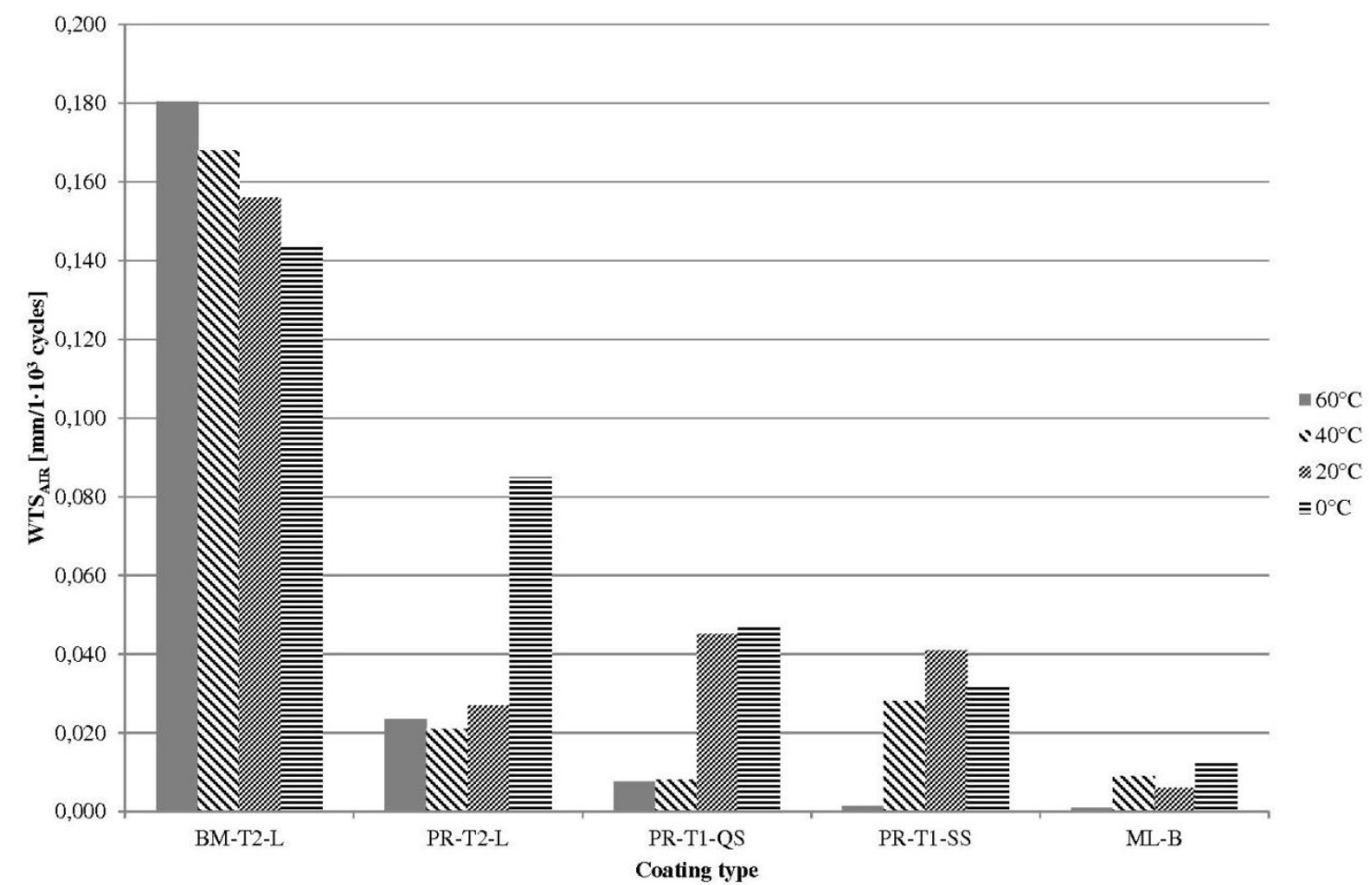

Figure 7. $\mathrm{WTS}_{\mathrm{AIR}}$ at $0^{\circ} \mathrm{C}, 20^{\circ} \mathrm{C}, 40^{\circ} \mathrm{C}$ and $60^{\circ} \mathrm{C}$ for several coating types

Lastly, the adhesion of the coating, polymeric and non-polymeric, to the concrete support was tested. The averages of three tests of adhesion were done for each type of pavement. The results, summarised in table 7, differed each time, even with the same specimen. This occurred mainly because the surface of the coating presented discontinuities that impeded the perfect attachment of the adhesive. In addition, even a slight inclination of the peg or the instrument led to non-homogeneous forces of traction on the specimen. 
Only in the case of the premixed type 2 envelope with steel slag waterproofing, did the failure of the specimen occur inside the concrete support, evidencing that the type 2 matrix with slags has a good internal cohesion. In fact, even if the stresses developed are high, the primer or the interface between primer and coating has almost always given way.

The asphalts have given a poorer performance than the other coatings: indeed, the bituminous layer was shown to have less adhesion to the concrete support than the primers used for the other solutions. In two cases, during the core sampling, just the rotation of the coring rig led to the waterproofing layer and the asphalt detaching from the support.

Table 7. Value of tensile stress and type of failure for each coating type

\begin{tabular}{|c|c|c|}
\hline $\begin{array}{l}\text { Coating } \\
\text { type }\end{array}$ & $\begin{array}{l}\text { Mean tensile } \\
\text { stress }[\mathrm{MPa}]\end{array}$ & Type of failure \\
\hline PR-T2-L & 1,44 & within the adhesive layer of the dowel \\
\hline PR-T2-SS & 1,39 & within the concrete substrate \\
\hline BM-T2-L & 0,70 & $\begin{array}{l}\text { at the interface between the concrete substrate and the } \\
\text { bituminous membrane }\end{array}$ \\
\hline BM-T2-SS & 0,76 & within the bituminous mixture \\
\hline PR-T1-QS & 1,59 & at the interface between the concrete substrate and the primer \\
\hline PR-T1-SS & 1,31 & within the primer \\
\hline PR-T1-RM & 0,91 & within the primer \\
\hline ML-QS & 1,53 & at the interface between the primer and the coating layer \\
\hline ML-SS & 1,48 & within the primer \\
\hline ML-RM & 0,97 & within the coating layer \\
\hline ML-B & 1,20 & the interface between the concrete substrate and the primer \\
\hline
\end{tabular}

The values of strength are globally higher for the solutions laid with the multi-layer method than with the premixed method, even if the solutions with quartz sand both obtained high values of tensile strength.

\section{CONCLUSIONS}

The research aim was to study pavements made with polymers for concrete decks on bridges. The performance of these coatings has been evaluated, through laboratory tests and data analysis, from the physical (surface characteristics) and mechanical (permanent deformations and adhesion to the support) points of view.

Overall, in terms of both macro-texture and Pendulum Test value, the multi-layer solution provides better surface characteristics than both the premixed solution and the traditional ones in asphalt.

This comparison suggests that coatings can be produced with the multi-layer system with better surface characteristics, but with a higher accumulation of permanent deformations than the premixed method. The cause of this behaviour is due to the aggregate grains not being completely immersed in the resin. In fact, the very rough surface of the coating confers antiskid properties on the system even in the worst 
cases, but renders the overall pavement weaker because of a greater presence of voids and the stresses that the tyre treads discharge directly on the single grains of the aggregate.

The premixed mixtures, therefore, have the strong point of being more resistant to high temperatures (that derives from the behaviour of the thermosetting resin used as binder), unlike the asphalts, which accumulate more permanent deformations.

The performances obtained with quartz sand (QS) and steel slags (SS) are better than those with recycled material (RM). In fact, this last type of aggregate develops less adhesion to the epoxy resin because it has a higher flakiness coefficient than the other types of aggregate.

In addition, it has been found that the use of a type 2 lithic matrix, similar to that used for an asphalt, with polymeric binders leads to worse characteristics than the premixed solutions. For these last types, a type 1 lithic matrix is used with a grading envelope that includes only fine material. The union of polymers and fine aggregate in the premixed solution has instead conferred poorer surface characteristics, but a lower accumulation of permanent deformations. The results of the adhesion tests suggest the need for further studies. 


\section{REFERENCES}

BABAEI, K. \& HAWKINS, N.M. (1988) "Evaluation of bridge deck proctetive strategies", ACI Concrete International, Vol. 10, No. 12, pp 56-66.

CALVO, L. \& MEYERS, M. (1991) "Overlay materials for bridge decks", ACI Concrete International, Vol. 13, No. 7, pp 48-49.

CARTER, P.D. (1997) "A procedure for determining performance of thin polymer overlays on Alberta bridge decks", ACI Special Pubblication, Vol. 169, pp 107-121.

DEPUY, G.W. \& DIMMICK, F.E. (2003) "Polymer concrete overlay for the repair and protection of concrete", ACI Special Pubblication, Vol. 214, pp 139-150.

DIMMICK, F.E. (1996) "15-year tracking study: comparing epoxy polymer concrete to Portland cement concrete applied on slab-on-grade and bridge decks", ACI Special publication, Vol. 166, pp 211-231.

DIMMICK, F.E. (1997) "Premixed epoxy polymer concrete bridge deck overlays", ACI Special Pubblication, Vol. 169, pp 146-171.

GILLUM, A.J., SHAHROOZ, B.M. and COLE, J.R. (2001) "Bond strength between sealed bridge decks and concrete overlays", ACI Structural Journal, Vol. 98, No. 6, pp 872-879.

KNIGHT, M.L. et al. (2004) "Overlay types used as preventive maintenance on Tennessee bridge deck", Transportation Research Record: Journal of the Transportation Research Board, National Research Council, Washington, D.C., 1866, pp 79-84.

MAASS, J. (2003) "How polyester polymer concrete highway and bridge deck overlays became state of the art", ACI Special Pubblication, Vol. 214, pp 39-50.

MENDIS, P. (1987) “A polymer concrete overlay”, ACI Concrete Internatinal, Vol. 9, No. 12, pp 54-56.

NABAR, S. \& MENDIS, P. (1997) "Experience with epoxy polymer concrete bridge deck thin overlays in service for over 10 year", ACI Special Pubblication, Vol. 169, pp 1-17.

PARK, H.M. et al. (2009) "Performance evaluation of a high durability asphalt binder and a high durability asphalt mixture for bridge deck pavements". Construction and Building Materials, Elsevier Ltd., Vol. 23, pp 219-225.

PASETTO, M. \& ZANUTTO, G. (1999) "Irruvidimenti superficiali con inerti e resine", Le Strade, La Fiaccola, Milano, 4, pp 72-76.

PASETTO, M., MODENA, C., SILVAN, S. and BRUNO P. (2000) "Impermeabilizzazione e pavimentazione di ponti e viadotti con trattamenti 
irruvidenti a base di malta sintetica", Proceedings of X National S.I.I.V. Congress, 2628 October, Catania, Italy, C.16 paper, p. 11.

PASETTO, M. \& BALDO, N. (2012) "Performance comparative analysis of stone mastic asphaltswith electric arc furnace steel slag: a laboratory evaluation". Materials and Structures, Vol. 45, pp 411-424.

PASETTO, M. \& GIACOMELLO, G. (2013) "The use of synthetic resins on concrete bridge decks", Proceedings of 17th International Conference on Environemental and Mineral Processing, 6-8. 6. 2013. VSB - Technical University of Ostrava, Czech Republic.

SILFWERBRAND, J. \& PAULASSON, J. (1998) "Better bonding of bridge deck overlays", ACI Concrete International, Vol. 20, No. 10, pp 56-61.

SPRINKEL, M. (1997) "Nineteen year performance of polymer concrete bridge", ACI Special Pubblication, Vol. 169, pp 42-74.

SPRINKEL, M. (2001) "Maintenance of concrete bridges", Transportation Research Record: Journal of the Transportation Research Board, National Research Council, Washington, D.C., Vol. 1749, pp 60-63.

STENKO, M.S. \& CHAWALWALA, A.J. (2001) "Thin polysulfide epoxy bridge deck overlays". Transportation Research Record: Journal of the Transportation Research Board, National Research Council, Washington, D.C., Vol. 1749, pp 64-67.

ZALATIMO, J.-A.H. \& FOWLER, D.W. (1997) "5-year performance of overlays in Fort Worth, Texas”, ACI Special Pubblication, Vol. 169, pp 122-145.

ZHOU, Q. \& XU, Q. 2009 "Experimental study of waterproof membranes on concrete deck: interface adhesion under influences of critical factors". Materials and design, Elsevier Ltd., Vol. 30, pp 1161-1168.

WHITE, D. \& MONTANI, R. (1997) "Thin-bonded polymer concrete overlays for exposed concrete bridge deck protection and maintenance", ACI Special Pubblication, Vol. 169, pp 99-106. 